\title{
Control hormonal y molecular del desarrollo de la glándula prostática
}

\section{Hormonal and molecular control of prostate gland growth}

Federico Perdomo Celis ${ }^{1}$, Manuel García Flórez ${ }^{2}$

Palabras clave: glándula prostática, pubertad, imprinting hormonal, disruptores endocrinos

Key words: prostate gland, puberty, hormonal imprinting, endocrine disr

\section{Resumen}

El control del crecimiento y de la fisiología prostática está basado en complejas interacciones de hormonas esteroides; específicamente son las vías metabólicas de su biosíntesis y degradación las que intervienen en el desarrollo de la glándula. También participan hormonas peptídicas $\mathrm{y}$ factores de crecimiento e interacciones entre el epitelio y el estroma. El desarrollo de la glándula prostática es caracterizado por una etapa de inducción prenatal, de ramificación ductal, diferenciación celular posnatal y otra de crecimiento durante la pubertad, esta última consecuencia de la producción testicular de testosterona (T). La conversión de T en dihidrotestosterona (DHT), por la acción de la enzima 5- $\alpha$-reductasa, es importante en el origen embrionario de la glándula. Esta dependencia androgénica es también demostrada en el adulto, donde la privación de esta hormona lleva a una drástica regresión de la glándula.

Además de andrógenos, otras hormonas como la progesterona y los estrógenos poseen acciones importantes en la fisiología prostática. Particularmente, este último es un factor regulador durante el desarrollo normal de la glándula, pero en determinadas situaciones se le ha asociado como agente inductor de algunas patologías durante el envejecimiento. Finalmente, la acción de enzimas como la aromatasa y de otras relacionadas con la conversión de T y de la DHT en compuestos sin actividad androgenica, como la $3 \beta$-hidroxi-esteroide deshidrogenasa ( $3 \beta$ HSD) y la $3 \beta$-adiol-hidroxilasa (CYP7B1) junto con la expresión coordinada de los receptores de hormonas esteroides ofrecen el equilibrio necesario para el desarrollo prostático normal.

Esta revisión se centra en la acción de hormonas esteroides en diferentes etapas del desarrollo prostático, y aborda la acción de disruptores endocrinos.

\footnotetext{
Abstract

Prostatic growth control and prostatic physiology are based on complex interactions among steroid hormones; specifically they are the metabolic pathways of their biosynthesis and degradation those that take part in the gland growth. Peptide hormones are also involved and growth factors and interactions between epithelium and stroma.

Prostatic development is characterized by a stage of fetal induction, of ductule branching. of postnatal cell differentiation and another stage of growth during puberty. The latter, is a consequence of testicular production of testosterone (T). Conversion of $\mathrm{T}$ into dihydrotestosterone (DHT), catalyzed by 5 - $\alpha$ reductase enzyme, is important for the embryonic origin of the gland. This androgenic dependence is also demonstrated in adults, on whom deprivation of this hormone leads to a drastic prostatic regression.
}




In addition to androgens, other hormones like progesterone and estrogens play important roles in prostate physiology. In particular, the latter is a regulatory factor during the normal development of the gland, but sometimes it has been considered as an inducing agent of some pathologies during aging process. Finally, enzyme action like aromatase and others related to T conversion and DHT in compounds with no androgenic activity, like the 3-hidroxi-steroid dehydrogenase (3-HSD) and the 3-adiol-hidroxilase (CYP7B1), along with the coordinate expression of steroid hormone receptors, supply the necessary balance for the normal prostatic development.

This review focuses on the action of steroid hormones in different stages of prostatic development. It also describes the general action of endocrine disruptors whose effect on sexual maturity depends on the administration period and on exposure time to them.

\section{Introducción}

\section{Morfología de la glándula prostática}

La glándula prostática se localiza en la base de la vejiga urinaria asociada íntimamente con la uretra. Clasificada como una glándula exocrina, su fisiología exige el acúmulo gradual y la expulsión rápida de volúmenes considerables de secreción ${ }^{(1)}$. Su función denota las características histológicas de la glándula y al microscopio se observa como un conjunto de estructuras túbulo-alveolares con capacidad de almacenamiento, rodeadas por un conjunto de células musculares que comprimen los ductos en el momento de la secreción ${ }^{(2)}$.

A diferencia de la glándula prostática humana, donde se reconocen diferentes zonas en una estructura compacta, en los roedores la glándula se divide en lóbulos constituidos por conjuntos de ductos, los cuales fueron originados como una estructura tubular simple, desde la uretra prostática, que se ramificó en sentido distal ${ }^{(3)}$.

Dependiendo de su posición con la uretra, en los ductos se reconocen diferentes regiones: una proximal, caracterizada por la presencia de células epiteliales cúbicas bajas rodeadas por una capa espesa de células musculares lisas, una intermedia, caracterizada por células columnares altas secretoras, y, una distal, en la que se presenta un epitelio columnar alto. Las cinéticas de proliferación y muerte celular varían igualmente de acuerdo a la región. La región proximal es carac- terizada por la presencia de células apoptóticas, mientras que en la distal predominan las células en división ${ }^{(4,5)}$.

De igual manera, el epitelio prostático se encuentra organizado de un modo jerárquico. Tres tipos celulares fenotípicamente distintos pueden encontrarse en la bicapa epitelial: células columnares luminales con función secretora, células basales relativamente indiferenciadas, y células neuroendocrinas dispersas ${ }^{(6)}$. Las células basales tienen una función regenerativa debido a su capacidad de pluripotencialidad; también se caracterizan por la expresión, entre otros, del marcador CD44, de la familia del receptor de Ácido Hialurónico, el cual ayuda en la fijación del epitelio prostático a la matriz extracelular (MEC). El estroma también expresa este marcador, demostrando así la comunicación y transmisión de señales existente entre la MEC y el epitelio (Figura 1).

\section{Desarrollo de la glándula prostática}

\section{Formación de los ductos genitales}

En el periodo ambisexual, aproximadamente en el décimo día de gestación en roedores y en la séptima semana en humanos, las gónadas en ambos sexos, hasta entonces no diferenciados, presentan una morfología idéntica. En esta fase del desarrollo, el fenotipo masculino es entonces determinado por la expresión del gen SRY o Región Determinante del Sexo en el cromosoma Y, 


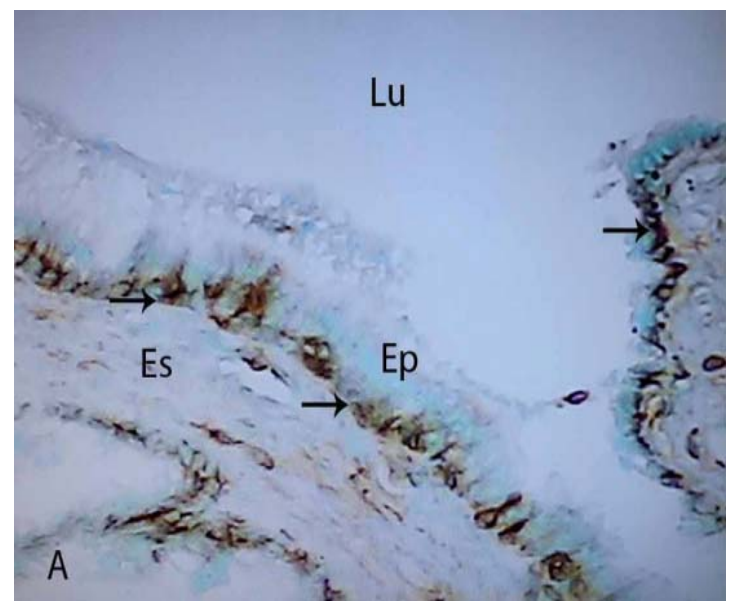

Figura 1. Corte de glándula prostática humana, reacción de inmunohistoquímica con tinción de verde de Metilo. Se observa la expresión del marcador CD44 (flechas), específico para células progenitoras, en el estrato basal (células basales) del epitelio prostático (Ep) y en el estroma (Es) de la glándula. $\mathrm{Lu}=$ Lumen prostático.

que determina la formación de las gónadas masculinas. Hasta este momento, los embriones indiferenciados poseen dos pares de ductos genitales: los mesonéfricos o de Wollf, que son precursores del sistema reproductor masculino, y los paramesonéfricos o de Muller, que originarán las estructuras del sistema reproductor femenino ${ }^{(7)}$.

En los machos alrededor de la sexta semana de gestación, las células de Sertoli de los testículos secretan la hormona antimulleriana que promueve la regresión de los ductos paramesonéfricos. Una semana más tarde la producción de testosterona aumenta por la acción de las células de Leydig, con lo que se estimula la formación de los ductos genitales masculinos a partir de los ductos mesonéfricos ${ }^{(8)}$.

En su parte proximal los ductos mesonéfricos adquieren forma de espiral dando origen al epidídimo, mientras que en su región distal adquieren un revestimiento espeso de músculo liso originando los ductos deferentes. Finalmente, una invaginación lateral del extremo caudal da origen a la vesícula seminal ${ }^{(8)}$.

\section{Inducción de la formación de la glándula prostática}

En las fases iniciales del desarrollo embrionario la región caudal del intestino pri- mitivo al dividirse origina dos estructuras: el canal anal, localizado dorsalmente, y el seno urogenital (SUG) en la región ventral. En este período en el SUG se pueden distinguir dos regiones, una epitelial (central) rodeada por una mesenquimal (lateral). En última instancia es la interacción entre estas regiones lo que determinará la formación de la glándula prostática ${ }^{(9,10)}$. La acción de los andrógenos en el mesénquima estimula la producción de factores inductores que actúan sobre el epitelio e inducen la formación de cordones en sentido distal donde posteriormente encontrarán el mesénquima(11). Siguiendo con su desarrollo, los cordones se ramifican y originan los ductos que forman los diferentes lóbulos y las diferentes zonas de la glándula prostática en roedores y en humanos respectivamente ${ }^{(12)}$ (Figura 2).

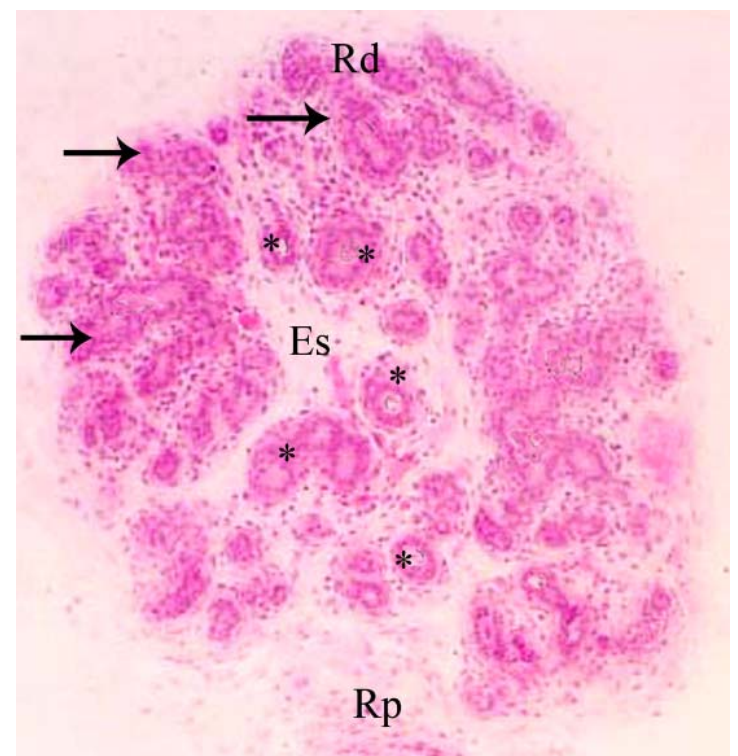

Figura 2. Características morfológicas de la glándula prostática en la fase posnatal. Corte transversal, tenido con $H \& E$, del lóbulo ventral de la próstata de roedores Wistar de una semana de vida donde se observan los ductos epiteliales inmaduros (asteriscos). La ramificación y diferenciación de las células progresa en sentido distal (flechas).

Es= estroma, $\mathrm{Rd}=$ Región distal, $\mathrm{Rp}=$ Región proximal.

Presente inicialmente en el mesénquima, el receptor de andrógeno (AR) es esencial para la diferenciación de la glándula prostática. Cuando las vías de señalización que involucran su participación son alteradas, ya sea por comprometimiento del 
receptor o por la ausencia del ligando específico (Testosterona o dihidrotestosterona), el desarrollo de la glándula, aunque presente, es afectado(11, 13-16).

Resulta interesante que la inducción prostática no es un evento genético pero sí hormono-dependiente(17); esto es evidente al observar que si el SUG femenino es estimulado en el período específico y con las concentraciones adecuadas de andrógenos, en él se desarrollan cordones epiteliales similares a los encontrados en el SUG de machos normales ${ }^{(18)}$. Aparentemente los andrógenos modulan negativamente una capa de músculo liso que actúa como una barrera entre epitelio y mesénquima e impide la comunicación paracrina entre estos compartimentos de embriones hembras ${ }^{(19)}$.

La formación de los cordones epiteliales que originan los ductos prostáticos ocurre alrededor de la décima semana de gestación ${ }^{(18,20)}$. Tres semanas más tarde, se pueden encontrar hasta 70 ductos principales y algunos incluso en proceso de diferenciación celular ${ }^{(11)}$. La diferenciación del estroma promueve la maduración del epitelio. Los andrógenos actúan sobre sus receptores localizados en el mesénquima urogenital (UGM) e inducen la producción de factores paracrinos que estimulan proliferación y diferenciación celular epitelial así como la ramificación de los ductos inmaduros ${ }^{(11,21)}$. En contrapartida, el epitelio prostático en desarrollo direcciona los patrones de diferen- ciación de músculo liso(22, 23). Ni el epitelio ni el músculo liso consiguen desarrollarse normalmente sin el estimulo del otro compartimento celular ${ }^{(12,24)}$.

Además de factores hormonales, las interacciones epitelio-mesenquima durante la organogénesis de la glándula prostática envuelve vías de señalización mediada por distintas familias de moléculas altamente conservadas. Se destaca la proteína sonic hedgehog(25-28), las proteínas morfogenéticas de hueso BMP (del inglés, Bone Morphogenetic Protein) ${ }^{(29)}$, los factores de crecimiento de fibroblastos 7 y 10 (FGF 7 y FGF10)(23), el Factor de Crecimiento Transformante $\beta$ $(\mathrm{TGF} \beta)^{(30)}$, proteínas de las familias Delta (ligandos) y Notch (receptores) $^{(31,32)}$, y varios genes Homeobox como son el gen $N k x 3.1$ de la familia $N k^{(33)}$, y los genes Hoxa13 y Hoxd-13 de la familia Hox ${ }^{(34)}$. (Tabla 1). La expresión de estos factores aumenta durante los primeros días de nacimiento, y es justamente en este período cuando la glándula sufre la formación de gran parte de sus ductos principales y donde también se presenta su intensa ramificación ${ }^{(29,31,34,35)}$.

\section{Expresión de los receptores de hormo- nas esteroides}

La testosterona es el principal andrógeno producido por las gónadas. Al reducirse, por la acción de la enzima $5 \alpha$ reductasa, origina

Tabla 1. Moléculas involucradas en el proceso de morfogénesis ductal de la glándula prostática.

\begin{tabular}{|c|c|}
\hline Moléculas & Acción \\
\hline Proteína Sonic Hedgehog & $\begin{array}{l}\text { Iniciación de la formación y diferenciación celular de los ductos } \\
\text { epiteliales }{ }^{(9)} \text {. }\end{array}$ \\
\hline Proteínas morfogenéticas de hueso & Regulación de la ramificación de los ductos ${ }^{(3)}$ \\
\hline Genes Hoxa-13 e Hoxd-13 & Morfogénesis ductal prostática ${ }^{(34)}$. \\
\hline Receptor de membrana Delta/ Notch-1 & $\begin{array}{l}\text { Expresión asociada con las células epiteliales progenitoras } \\
\text { prostáticas }{ }^{(31)} \text {. }\end{array}$ \\
\hline Genes $N k x 3.1$ & $\begin{array}{l}\text { Diferenciación celular epitelial (Células epiteliales luminares } \\
\text { y basales) }{ }^{(33)} \text {. }\end{array}$ \\
\hline Factor de crecimiento de fibroblastos 7 y 10 & $\begin{array}{l}\text { Acción mitogénica sobre el epitelio durante el desarrollo } \\
\text { prostático }\end{array}$ \\
\hline Factor de crecimiento transformante $b$ & $\begin{array}{l}\text { Estimula la proliferación epitelial en la región distal y actúa como } \\
\text { factor regulador en la región proximal prostática }{ }^{(15)} \text {. }\end{array}$ \\
\hline
\end{tabular}


la dihidrotestosterona (DHT), quien tiene una importante participación en el desarrollo de la glándula al direccionar su morfogénesis ${ }^{(36,37)}$.

La producción testicular de andrógenos en los fetos comienza antes y continúa durante la morfogénesis prostática ${ }^{(38)}$. En este mismo período los testículos fetales alcanzan su máxima concentración de andrógenos, la cual permanece elevada hasta la $18^{a}$ semana de gestación, cuando declina y se estabiliza hasta el inicio de la pubertad, aumentando nuevamente $(15,38)$.

Las respuestas celulares de los andrógenos sistémicos son mediadas por la interacción con sus receptores (ARs). Las vías de señalización relacionadas con el complejo andrógeno-AR son determinantes para que exista una completa inducción de la glándula prostática. Así, las alteraciones en la expresión del gen del AR comprometen al receptor y afectan el desarrollo prostático ${ }^{(39)}$. Por otro lado, cuando la acción de la enzima $5 \alpha$ reductasa es inhibida, la conversión de $\mathrm{T}$ en DHT disminuye, y aunque haya el direccionamiento de un SUG indiferenciado hacia la formación de la glándula prostática, ésta puede ser rudimentaria en la edad adulta.

También es importante la interacción de andrógenos y estrógenos en la fisiología de la glándula. Ya que se puede demostrar la frecuente co-localización de sus receptores en las células epiteliales y estromales, se sugiere una participación coordinada entre concentraciones hormonales y presencia de receptores en ambos compartimentos.

La glándula prostática desarrollada y en condiciones normales posee la expresión del AR en la totalidad de los núcleos de las células epiteliales luminares y en la mitad, aproximadamente, de las células epiteliales basales. Las células estromales, especialmente las musculares lisas, presentan, aunque en forma menos expresiva, también una inmunomarcación positiva ${ }^{(40)}$. A lo largo de los ductos prostáticos no existe una diferencia significativa de la expresión del AR, lo que sugiere que las diferentes respuestas que involucran hormonas esteroides son medidas indirectamente por factores paracrinos y no por la expresión regional diferenciada del $\mathrm{AR}^{(41)}$.
Por otro lado, la acción de los estrógenos en la próstata es dada principalmente a través de las isoformas alfa y beta de los receptores de estrógeno (ER $\alpha$ y ER $\beta)$. La expresión del ER $\alpha$ ha sido reportada en las células del estroma $^{(42)}$, mientras que el ER $\beta$ es principalmente encontrado en las células epiteliales y esporádicamente en las células estromales próximas a los acinos ${ }^{(43)}$ (Figura 3).

En la próstata inmadura, alrededor de la $11^{a}$ semana de gestación, la expresión del $A R$ es detectada exclusivamente en el estroma prostático. Solamente cinco semanas después, alrededor de la $16^{a}$, se detecta en el epitelio inmaduro. Poco antes del nacimiento la expresión del AR disminuye en las células epiteliales pero se mantiene en el estroma, principalmente en las células musculares lisas. Dos semanas después del nacimiento la expresión del AR es detectada nuevamente en el epitelio ${ }^{(24)}$.

La expresión del ER $\beta$ aparece en la $13^{\mathrm{a}}$ semana de gestación, aumentando paralelamente con la concentración de estrógeno durante la mitad del período gestacional. Contrariamente, el ER $\alpha$ en humanos parece tener poca participación en los eventos iniciales del desarrollo prostático, ya que su detección ocurre alrededor de la cuarta semana de vida postnatal cuando se le detecta en las células de la región periacinar ${ }^{(24)}$.

$\mathrm{Al}$ nacer los mamíferos pierden su contacto con la placenta, lo que produce un nuevo ambiente hormonal. Se produce disminución de las concentración séricas de estrógenos, progesterona, gonadotrofina coriónica humana (hCG) y hormona lactogénica placentaria $(\mathrm{hPL})^{(8)}$, mientras que la concentración de hormona luteinizante aumenta ( $\mathrm{LH})$ y estimula la producción de testosterona en los machos. Esta concentración elevada de testosterona en los primeros días de vida posnatal influye directamente en eventos relacionados a la morfogénesis de la glándula ${ }^{(45)}$. Durante este mismo período se puede acelerar el crecimiento de la próstata al aplicar testosterona exógena y llevándola a alcanzar precozmente su crecimiento máximo ${ }^{(46)}$. Por el contrario, la castración inhibe el crecimiento y el desarrollo de la próstata, efecto que puede ser revertido con la administración de testosterona ${ }^{(10,45)}$. 


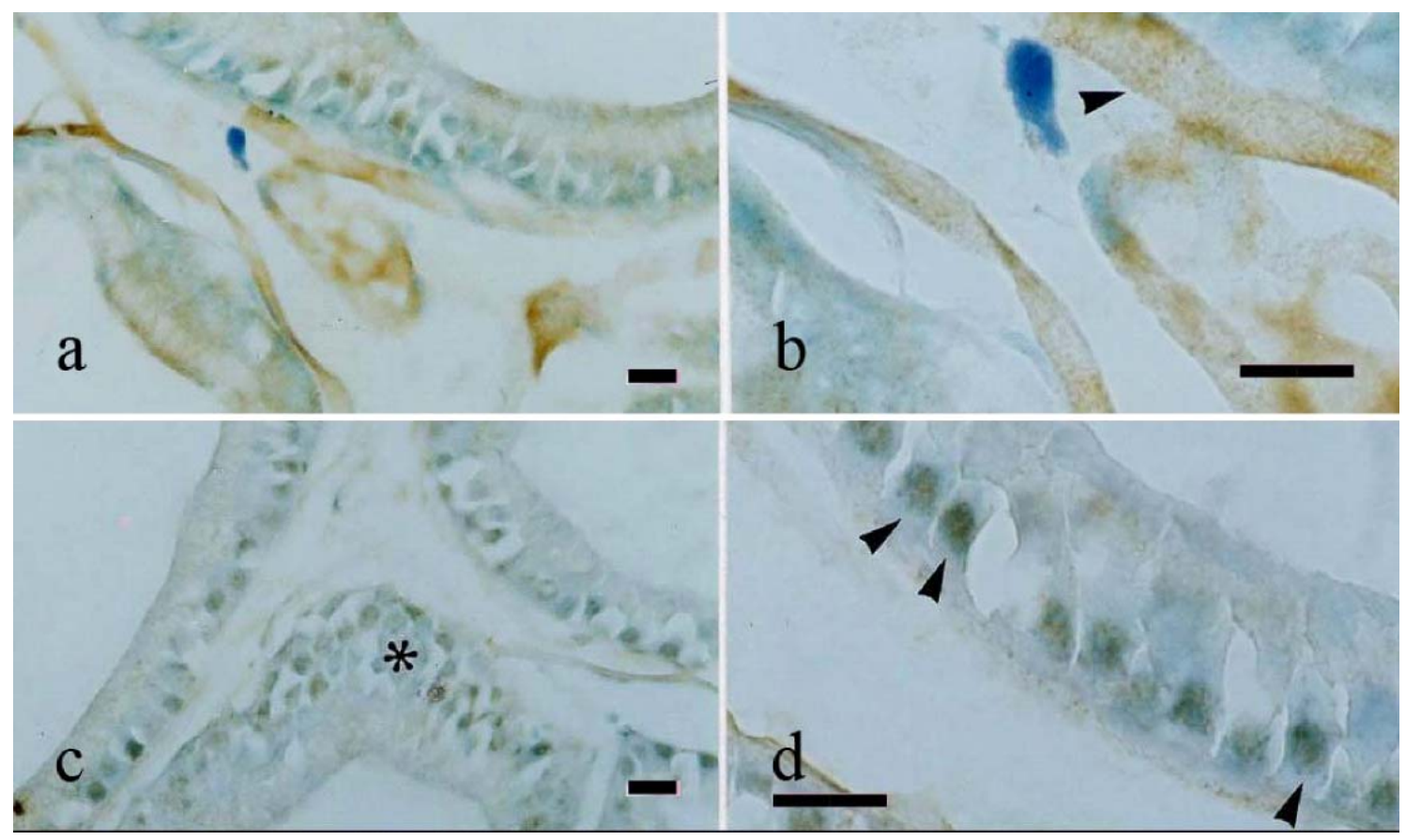

Figura 3. Expresión de los receptores de estrógeno en la glándula prostática. Corte transversal en congelación del lóbulo ventral de la glándula prostática de un roedor Wistar adulto (90 días). La reacción inmunocitoquímica revela la presencia del receptor de estrógeno alfa (ERa) principalmente en las células estromales del tejido (a y b), por otro lado, el receptor de estrógeno beta $(\mathrm{ERb})$ es identificado en los núcleos de las células epiteliales (c y d). Barras $=100 \mathrm{~mm}$.

Dependiendo del periodo de desarrollo, la glándula prostática responde al estímulo hormonal(12): en el período neonatal el estímulo hormonal induce principalmente la ramificación $\operatorname{ductal}^{(12,46)}$, pero en un estadio más avanzado, como la pubertad, las concentraciones elevadas de andrógenos estimulan principalmente el aumento de peso seco de la glándula y, aunque presente, el aumento de las ramificaciones ductales es reducido ${ }^{(13,47)}$.

\section{Endocrinología prostática}

Como ya se ha mencionado, la conversión de $\mathrm{T}$ en el más potente andrógeno intracelular, la $5 \alpha$-dihidrotestosterona (DHT), se produce por la acción de la enzima $5 \alpha$-reductasa. Dos tipos de $5 \alpha$-reductasa han sido identificados: la $5 \alpha$-reductasa tipo I, que se encuentra en la mayoría de los tejidos, y la $5 \alpha$-reductasa tipo II que predomina en los tejidos genitales, incluyendo la $\operatorname{próstata}^{(48)}$.

La DHT intracelular es rápidamente metabolizada en una reacción reversible a
$3 \alpha, 17 \beta$-androstenediol ( $3 \alpha$-diol), o a $3 \beta$, $17 \beta$-androstenediol ( $3 \beta$-adiol). La enzima responsable por esta vía de inactivación es

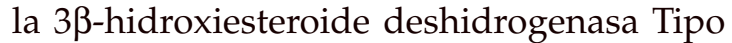

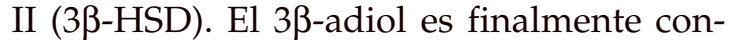
vertido irreversiblemente en esteroides inactivos hidrosolubles, por la acción de la $3 \beta$-adiolhidroxilasa (CYP7B1) ${ }^{(49)}$ (Figura 4).

Para el tratamiento de la hiperplasia prostática (BPH), crecimiento benigno de la glándula, es usada la finasterida, un inhibidor específico de la $5 \alpha$-reductasa tipo II. Con este medicamento se consigue una disminución del 70\% de las concentraciones séricas de DHT y de un $90 \%$ de las concentraciones en la próstata(50). La cantidad remaneciente de DHT en la próstata es atribuida a la reducción de la testosterona por parte de la isoenzima tipo I.

Inicialmente, la acción de la finasterida bloquea la producción de DHT, llevando a una disminución del crecimiento prostático. Sin embargo, la inhibición de la $5 \alpha$ reductasa Tipo II causa el acúmulo de testosterona, aumentando la expresión del AR en la próstata y causando un efecto pro- 


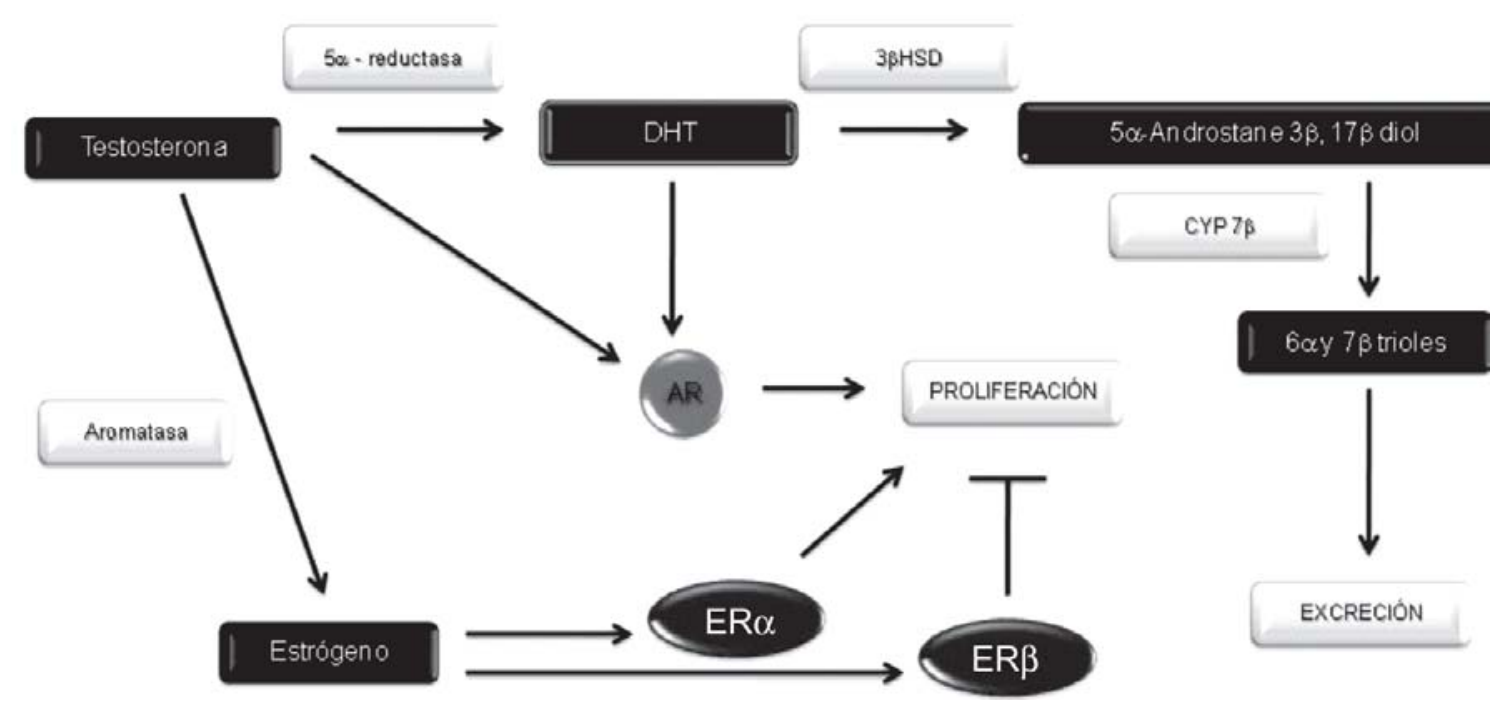

Figura 4. Relaciones entre andrógenos y estrógenos en la glándula prostática. La testosterona tiene un papel fundamental en la fisiología prostática. En el órgano ella es convertida en dihidrotestosterona (DHT) por la enzima 5a-reductasa. Tanto la testosterona como la DHT se unen al receptor de andrógeno, promoviendo la proliferación de las células epiteliales. Su acción sobre las células estromales es variable, dependiendo del tipo celular considerado. La DHT es normalmente convertida a 5a-androstane 3b, 17bdiol, por la enzima 3bhidroxiesteroide deshidrogenasa Tipo II (3bHSD). El exceso de 5a-androstane $3 b, 17 b d i o l$ es procesado por la enzima 3bAdiol hidroxilasa (CYP7B1) y lo convierte en $6 a$ y $7 \mathrm{~b}$ trioles, que son eliminados. En los machos, el estrógeno circulante se origina por a acción de la enzima aromatasa sobre la testosterona. AR= Receptor de andrógeno; $\mathrm{ERa}=$ Receptor de estrógeno subtipo a, ERb= Receptor de estrógeno subtipo b.

motor $^{(51)}$. La aromatasa puede convertir el exceso de testosterona en estrógeno, el cual actúa sobre los receptores ER $\alpha$ y ER $\beta$, quizá resultando en un crecimiento displásico de la próstata.

\section{Estrógenos y próstata}

\section{Acción del estrógeno en la glándula prostática}

En un estudio pionero, se demostró la dependencia androgénica de la glándula prostática para los procesos de inducción, diferenciación y mantenimiento de su acción fisiológica ${ }^{(52)}$. Desde entonces, los estudios se han direccionado sobre las vías metabólicas de la testosterona, incluyendo las isoformas responsables por su reducción a dihidrotestosterona (DHT).

Esta visión ha sido también reforzada por los conceptos tradicionales que hacen una fuerte separación entre hormonas masculinas para andrógenos y femeninas para estrógenos. Contrario a esta creencia, la presencia de las dos for- mas de receptor de estrógeno (ER $\alpha$ y ER $\beta)$ en el tracto reproductor masculino -testículos, ductos eferentes, epidídimo, próstata, glándulas bulbo-uretrales y vesícula seminal-sugiere la acción de los estrógenos en estos órganos ${ }^{(53)}$.

Los efectos del estrógeno exógeno en la glándula pueden ser indirectos cuando afectan el equilibrio del eje hipotálamo-hipófisis y causan atrofia testicular, lo que lleva a la disminución en la producción de $\mathrm{T}^{(54)}$, o también directos al inducir apoptosis precoz de las células epiteliales. En condiciones de castración la muerte celular de las células epiteliales es fuertemente inducida en el tercer día, cuando las concentraciones de testosterona han caído notablemente; intrigantemente, posterior al tratamiento con dosis supra fisiológicas de estrógeno la muerte celular se anticipa al segundo día ${ }^{(55)}$.

El paso final de la biosíntesis de estrógeno a partir de la testosterona es catalizado por la enzima aromatasa (CYP19A1), enzima involucrada en la transformación irreversible de andrógenos en estrógenos y que está presente en el retículo endoplasmático de numerosos tejidos ${ }^{(56)}$. En las células 
epiteliales y estromales de la próstata humana se ha localizado la aromatasa y otras enzimas involucradas en el metabolismo de los estrógenos. Además, estos tipos celulares expresan el receptor de estrógeno, especialmente el ER $\beta$, lo que sugiere un modelo de autorregulación ${ }^{(57)}$. El aumento en el contenido de estrógeno es reportado en la próstata desde la 16a semana hasta el final de la gestación, cuando cae abruptamente debido a la falta de la síntesis materna y placentaria ${ }^{(58)}$.

Otro ejemplo de la influencia de los estrógenos en el desarrollo prostático ocurre durante la gestación de los roedores. En el útero de la gestante los fetos masculinos y femeninos son dispuestos aleatoriamente, y por su gran numero (8 a 12 fetos en promedio), mantienen un íntimo contacto entre ellos, lo que conlleva a un flujo de hormonas esteroides a través del drenaje venoso entre fetos adyacentes ${ }^{(59)}$. La exposición hormonal para cada feto varía de acuerdo con el sexo de los fetos adyacentes. Así, los fetos situados entre hembras (denominados $2 \mathrm{~F}$ ) son influenciados estrogénicamente, mientras que los fetos localizados entre machos (denominados $2 \mathrm{M}$ ) están bajo la influencia androgénica(16) (Figura 5). La exposición hormonal durante la fase fetal influye en el desarrollo neural y sexual, condicionando las respuestas a los estímulos hormonales en la fase adulta ${ }^{(60)}$.

En las hembras, la exposición elevada a los estrógenos como consecuencia de la posición intrauterina estimula la precocidad del primer ciclo estral, hecho asociado con la primera ovulación postpubertal ${ }^{(61)}$. De forma interesante, existen diferencias en la organogénesis de la glándula de los machos 2F cuando se comparan con machos menos expuestos a los estrógenos (2M o FM), observando en los primeros un aumento en las áreas de los brotes prostáticos que originan los diferentes lóbulos ${ }^{(16)}$. El aumento del estrógeno circulante en los machos $2 \mathrm{~F}$, aproximadamente $30 \%$ más alto que en fetos $2 \mathrm{M}$, sería el responsable de sensibilizar la respuesta de las células prostáticas a los andrógenos por medio de dos mecanismos posibles: 1) produciendo un aumento del número de receptores de andrógeno (aproxi-

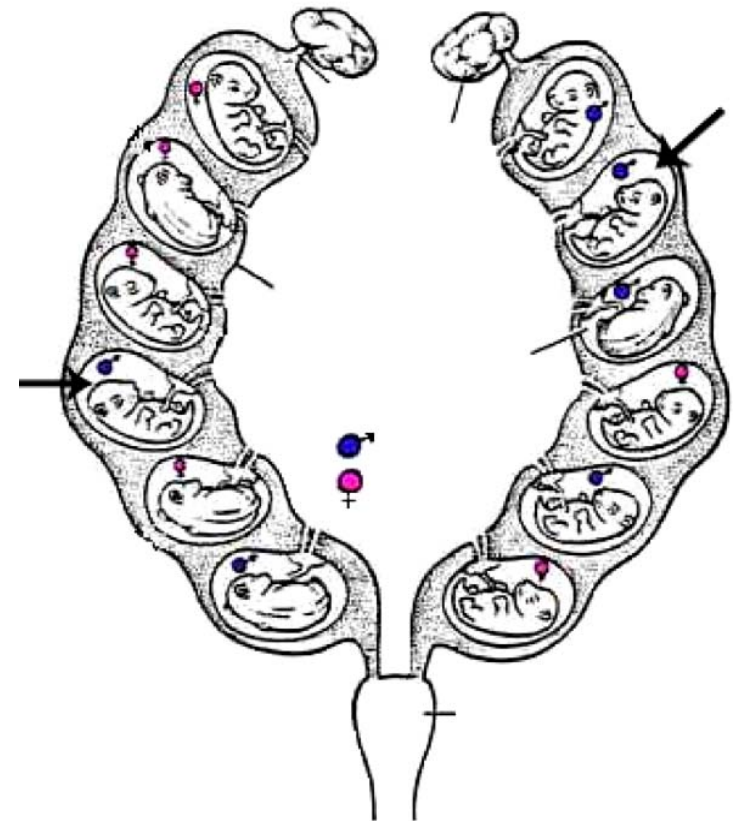

Figura 5. Distribución de los fetos en los cuernos uterinos durante la gestación. Los fetos en cada cuerno son clasificados de acuerdo con su proximidad a la posición caudal. MM (2M) y FM son fetos con influencia masculina; MF y FF (2F) son fetos con influencia femenina; M0 y F0 son fetos localizados proximalmente al cérvix (Adaptado de Nonneman y colaboradores $(68)$ ).

madamente de tres veces) y 2) generando una mayor afinidad de los receptores de andrógeno por sus ligandos ${ }^{(60)}$.

\section{Imprinting hormonal y acción de disruptores endocrinos}

Aunque la morfogénesis de la glándula prostática de roedores sea iniciada durante la fase fetal, la mayor parte de la ramificación ductal y diferenciación celular ocurre en el período neonatal ${ }^{(62)}$. Está bien establecido que en esta fase algunos eventos pueden ser "memorizados" por las células, un fenómeno denominado imprinting hormonal. Factores hormonales durante las primeras etapas de la vida parecen influir en la ocurrencia de enfermedades en las últimas etapas de la misma. Es el caso de la deficiencia de andrógenos en varones castrados o con deficiencia de la $5 \alpha$ reductasa, donde no se desarrolla enfermedad prostática en la vejez. Los mecanismos de esos efectos latentes pueden ser explicados mediante el imprinting hormonal( ${ }^{(63)}$. Durante el desarro- 
llo, los receptores ER $\alpha$ y ER $\beta$ se expresan en el estroma y epitelio respectivamente ${ }^{(64)}$, y además están asociados con acciones opuestas: las señales proliferativas y de diferenciación son mediados a través del ER $\alpha$ y las señales de regulación de la proliferación ocurren a través del ER $\beta$ cuando se une al 3ß-adiol, un metabolito de la $\mathrm{DHT}^{(65)}$.

En un estudio se investigaron las bases moleculares y estructurales del imprinting estrogénico neonatal usando un modelo murino. En este, una dosis neonatal única de estrógenos demostró efectos en la arquitectura glandular y composición anatómica de la próstata ventral (VP) madura en los ratones machos: hubo un efecto regresivo en la morfogénesis ductal cuando se les administró Benzoato de Estradiol (EB) y Dietilestilbestrol (DES) en presencia o no de anti-estrógenos (Tamoxifen e ICI 182 780), lo cual se reflejó en reducción del peso de la VP a pesar del efecto hiperplásico epitelial y fibromuscular estromal del DES. De igual manera, la administración de antagonistas de la hormona liberadora de Gonadotrofinas (GnRh-A) disminuyó el peso, la ramificación ductal y el tamaño de la VP, proporcionando así un eficaz control de los efectos indirectos de los estrógenos mediados por la supresión de gonadotrofinas ${ }^{(66)}$.

Una vez formado, el complejo estrógeno-receptor regula procesos de transcripción génica al unirse a elementos responsivos estrogénicos (EREs) localizados en determinados genes, a través de coactivadores como el complejo CBP/p300. Estos complejos poseen actividad acetiltransferasa que relaja la cromatina y permite la unión de complejos responsables por el inicio de la transcripción de genes específicos ${ }^{(67,68)}$.

La respuesta a los estrógenos es debida entonces a la presencia o no de las isoformas de los receptores $(\alpha$ y/o $\beta)$ así como a la de complejos de coactivadores, que presentan diferentes acciones sobre la estructura cromatínica, en los diferentes tipos celulares ${ }^{(69)}$. El imprinting estrogénico puede producirse por la exposición hormonal inadecuada en periodos sensibles del desarrollo de la glándula; esto altera la expresión de los coactivadores y afecta la correcta unión de los complejos estrógeno-receptor a los $\operatorname{EREs}^{(70)}$. De esta forma en períodos posteriores del desarrollo, la señalización celular de hormonas esteroides o de sustancias que mimeticen su acción puede presentarse de forma alterada, promoviendo crecimientos descontrolados en el teji$\mathrm{do}^{(71)}$.

La ventana de sensibilidad a la exposición a estrógenos de la glándula prostática ocurre durante los primeros días de vida; la exposición en este período causa alteraciones en el crecimiento de la glándula durante la pubertad y en la edad adulta. Por otro lado, la exposición previa a la pubertad causa efectos menos dramáticos en la fisiología de la glándula en la edad adulta (GarcíaFlórez M, Oliveira CA, Carvalho HF. Resultados no publicados).

Para determinar un posible rol sinergístico de las andrógenos y estrógenos en el desarrollo postnatal de la próstata, se diseñó un estudio en ratones HPG (hipogonadales), caracterizados por la deficiencia androgénica completa pero con total respuesta a andrógenos exógenos. Una dosis única neonatal de andrógenos (testosterona) incrementó la ramificación ductal y el peso de la VP comparada con los no tratados. Por otro lado, el estrógeno neonatal solo no tuvo ningún efecto. En los ratones HPG tratados con los andrógenos no aromatizables (DHT y Nandrolona) se incrementó el tamaño de las vesículas seminales comparados con los no tratados, mientras que el Benzoato de Estradiol fue inefectivo. Este patrón de respuesta en el cual todos los andrógenos, pero no los estrógenos, tienen efectos estimulatorios indica que probablemente el modo de acción de los andrógenos es a través del AR y que la aromatización puede no ser esencial para el imprinting androgénico neonatal de la próstata ${ }^{(72)}$.

\section{Conclusiones}

La compleja interacción entre hormonas, receptores y cofactores es un proceso secuencial y finamente regulado en los tejidos que responden al estímulo hormonal. De forma general la hormona esteroide se difunde pasivamente a través de la mem- 
brana celular, entrando al citoplasma donde encuentra el receptor correspondiente y forma el complejo hormona-receptor. A pesar de que las hormonas esteroides poseen una estructura de cuatro anillos, derivadas del colesterol, solamente uno de estos (el anillo A) se acopla al sitio específico de unión con su receptor. Una vez formado el complejo, este entra en el núcleo y se une a elementos responsivos de hormonas en el ADN promoviendo así la transcripción de genes específicos. La hormona que normalmente forma el complejo hormona-receptor, puede ser fácilmente sustituida por sustancias con estructura similar (contaminantes, pesticidas, desechos industriales) y puede formar un complejo con el receptor que mimetiza la acción hormonal. También el complejo puede formarse en un periodo de desarrollo no adecuado al existir una exposición prematura a las hormonas. En los dos casos anteriores se producen daños en las vías de señalización celular que posiblemente son la causa de muchas de las patologías del tracto reproductor con etiología aún desconocida. Tanto los andrógenos como los estrógenos contribuyen significativamente en la regulación del desarrollo, crecimiento y mantenimiento de los órganos sexuales masculinos, siendo la próstata un blanco específico para las vías de proliferación o regresión del epitelio promovidas por éstas hormonas. Estos mecanismos moleculares, genéticos y epigenéticos determinan el desarrollo de la glándula en las primeras etapas de la vida, y podrían estar relacionadas con la patogenia de sus trastornos neoplásicos.

\section{Agradecimientos}

Los autores agradecen a la Vicerrectoría de Investigación de la Universidad Surcolombiana por la financiación y apoyo en el desarrollo de la investigación.

\section{Referencias Bibliográficas}

1. McNeal JE. 1997. Prostate. In: Histology for Pathologist. 2nd edn. Edited by Stephen S.
Stemberg. Lippincontt-Raven Publishers, Philadelphia.

2. Aümuller G. 1979. Prostate gland and seminal vesicles. In: Handbuch der mikroskopischen Anatomie des Menschen. Edited by A. Okche and L. Vollrath. Berlin-Heidelberg, New York: Springer-Verlag, pp.12-24.

3. Almahbobi G., Hedwards S., Fricout G., Jeulin D., Bertram JF., Risbridger GP. 2005. Computer-based detection of neonatal changes to branching morphogenesis reveals different mechanisms of and predicts prostate enlargement in mice haploinsufficient for bone morphogenetic protein 4. Journal of Pathology, 206: 52-61.

4. Lee C., Sensibar JA., Dudek SM., Hiipakka RA., Liao S. 1990. Prostatic ductal system in rats: Regional variation in morphological and functional activities. Biology of Reproduction, 43:1079-1086.

5. Shabsigh A., Tanji N., D'agati V., Burchardt T., Burchardt M., Hayek O., Shabsigh R., Buttyan R. 1999. Vascular anatomy of the rat ventral prostate. Anatomical Record, 256: 403-411.

6. Oldridge, E.E., et al. 2011. Prostate cancer stem cells: Are they androgen-responsive?. Molecular and Cellular Endocrinology, doi:10.1016/j.mce.2011.07.008

7. Grumbach MM., Hughes IA., Conte FA. 2003. Disorders of Sex Differentiation. In: Williams textbook of endocrinology. 10th ed. Elsevier Philadelphia, Pennsylvania, pp. 842-1002.

8. Fisher DA. 2003. Endocrinology of Fetal Development. In: Williams textbook of endocrinology 10th ed. Copyright (c) Elsevier Philadelphia, Pennsylvania. pp. 811-841.

9. Berman DM., Desai N., Wang X., Karhadkar SS., Reynon M., Abate-Shen C., Beachy PA., Shen MM. 2004. Roles for Hedgehog signaling in androgen production and prostate ductal morphogenesis. Developmental Biology, 267: 387-398.

10. Staack A., Donjacour AA., Brody J., Cunha GR., Carrol P. 2003. Mouse urogenital development: a practical approach. Differentiation, 71: 402-413.

11. Cunha GR., Donjacour AA., Cooke PS., Mee S., Bigsby RM., Higgins SJ., Sugimura Y. 1987. The endocrinology and developmental biology of the prostate. Endocrine Reviews, 8: 338-362.

12. Hayward SW. \& Cunha GR. 2000. The prostate: Development and physiology. Radiologic Clinics of North America, 38: 1-14.

13. Sugimura Y, Cunha GR., Donjacour AA. 1986. Morphogenesis of ductal networks in the mouse prostate. Biology of Reproduction, 34: 961-971. 
14. Hayashi N., Sugimura Y., Kawamura J., Donjacour AA., Cunha GR. 1991. Morphological and functional heterogeneity in the rat prostatic gland. Biology of Reproduction, 45: 308-321.

15. Timms TL., Truong LD., Merz VW., Krebs T., Kadmon D., Flanders KC., Park SH., Thompson TC. 1994. Mesenquimal-epithelial interactions and transforming growth factor$\mathrm{b}$ expression during mouse prostate morphogenesis. Endocrinology, 134: 1039-1045.

16. Timms BG., Petersen SL., Vom Saal FS. 1999. Prostate gland growth during development is stimulated in both male and female rat fetuses by intrauterine proximity to female fetuses. The Journal of Urology, 161: 1694-1701.

17. Takeda I., Lasnitzki I., Mizuno T. 1986. Analysis of prostatic bud induction by brief androgen treatment in the fetal rat urogenital sinus. Journal of Endocrinology, 110: 467-470.

18. Marker PC., Donjacour AA., Dahiya R., Cunha GR. 2003. Hormonal, cellular, and molecular control of prostatic development. Developmental Biology, 253: 165-174.

19. Thomson AA., Timms BG., Barton L., Cunha GR., Grace OC. 2002. The role of smooth muscle in regulating prostatic induction. Development, 129: 1905-1912.

20. Chrisman H., Thomson AA. 2005. Regulation of urogenital Smooth Muscle patterning by testosterone and estrogen during prostatic induction. The prostate, 66: 1-12.

21. Cunha GR., Alarid ET., Turner T., Donjacour AA., Boutin EL., Foster BA. 1992. Normal and abnormal development of the male urogenital tract: Role of androgens, mesenchymal-epithelial interactions, and growth factors. Journal of Andrology, 13: 465-75.

22. Hayward SW., Haughney PC., Rosen MA., Greulich KM., Weier HU., Dahiya R., Cunha GR. 1998. Interactions between adult human prostatic epithelium and rat urogenital sinus mesenchyme in a tissue recombination model. Differentiation, 63: 131-140.

23. Thomson AA. 2001. Role of androgens and fibroblast growth factors in prostate development. Biology of Reproduction, 121: 187-195.

24. Adams, J.Y., Leav, I., Lau, K.M., Ho, S.M., Pflueger, S.M.V. 2002. Expression of estrogen receptor beta in the fetal, neonatal, and prepubertal human prostate. The prostate, 52 : 69-81.

25. Podlasek, C.A., Barnett DH., Clemens JQ., Bak PM., Bushman W., 1999. Prostate development requires Sonic hedgehog expressed by the urogenital sinus epithelium. Developmental Biology, 209: 28-39.

26. Lamm M., Catbagan W., Laciak R., Barnett D., Hebner C., Gaffield W., Walterhouse D.,
Iannaccone P., Bushman W. 2002. Sonic hedgehog activates mesenchymal Gli1 expression during prostate ductal bud formation. Developmental Biology, 249: 349- 366.

27. Wang BE., Shou J., Ross S., Koeppen H., De Sauvage F.J., Gao W.Q. 2003. Inhibition of epithelial ductal branching in the prostate by sonic hedgehog is indirectly mediated by stromal cells. The Journal of Biological Chemistry, 278: 18506- 18513.

28. Freestone SH., Marker P., Grace OC., Tomlinson D.C., Cunha GR., Harnden P., Thomson AA. 2003. Sonic hedgehog regulates prostatic growth and epithelial differentiation. Developmental Biology, 264: 352-362.

29. Lamm M.L., Podlasek C.A., Barnett D.H., Lee J., Clemens J.Q., Hebner C.M., Bushman W. 2001. Mesenchymal factor bone morphogenetic protein 4 restricts ductal budding and branching morphogenesis in the developing prostate. Developmental Biology, 232: 301- 314.

30. Ball EMA. \& Risbridger GP. 2001. Activins as Regulators of Branching Morphogenesis. Developmental Biology, 238: 1-12.

31. Wang XD., Shou J., Wong P., French DM., Gao WQ. 2004. Notch1- expressing cells are indispensable for prostatic branching morphogenesis during development and re- growth following castration and androgen replacement. The Journal of Biological Chemistry, 279: 24733-24744.

32. Shou J., Ross S., Koeppen H., De Sauvage FJ., Gao WQ. 2001. Dynamics of notch expression during murine prostate development and tumorigenesis. Cancer Research, 61: 7291-7297.

33. Huang L., Yongbing P., Alam S., Birch L., Prins GS. 2004. Estrogenic regulation of signaling pathways and homeobox genes during rat prostate development. Journal of Andrology, 25: 330-337.

34. Podlasek CA., Clemens JQ., Bushman W. 1999. Hoxa-13 Gene Mutation results in abnormal seminal vesicle and prostate development. The Journal of Urology, 161: 1655-1661.

35. Thomson AA., Foster BA., Cunha GR. 1997. Analysis of growth factor and receptor mRNA levels during development of rat seminal vesicle and prostate. Development, 124: 2431-2439.

36. Taplin ME., e Ho S-M. 2001. The endocrinology of the prostate cancer. The Journal of Clinical Endocrinology and Metabolism, 86: 3467-3477.

37. Wilson JD., Griffin JE., George FW., Leshin M. 1983. The endocrine control of male phenotypic development. Australian Journal of Biological Sciences, 36: 101-128. 
38. Pointis G., Latreille MT., Cedard L. 1980. Gonado-pituitary relationships in the fetal mouse at various times during sexual differentiation. Journal of Endocrinology, 86: 483-488.

39. Brown TR., Berkovitz GD., Gearhart JP. 1988. Androgen receptors in boys with isolated bilateral cryptorchidism. American Journal of Diseases of Children, 142: 933-936.

40. Mirosevich J., Bentel JM., Zeps N., Redmond SL., D' Antuono MF. 1999. Androgen receptor expression of proliferating basal and luminal cells in adult murine ventral prostate. Endocrinology, 162: 341-350.

41. Prins GS., Cooke PS., Birch L., Donjacour AA., Yalcinkaya TM., Siiteri PK., Cunha GR. 1992. Androgen receptor expression and 5aredutase activity along the proximal-distal axis of the rat prostate duct. Endocrinology, 129: 3187-3199.

42. Bonkhoff H., Fixemer T., Hunsicker I., Remberg K. 1999. Estrogen receptor expression in prostate cancer and premalignant prostate lesions. American Journal of Pathology, 155: 641-647.

43. Pasquali D., Staibano S., Prezioso D., Franco R., Esposito D., Notaro A., De Rosa G., Bellastella A., Sinisi AA. 2001. Estrogen receptor b expression in human prostate tissue. Molecular and Cellular Endocrinology, 178: 47-50.

44. Prins GS., Birch L. 1995. The developmental pattern of androgen receptor expression in rat prostate lobes is altered after neonatal exposure to estrogen. Endocrinology, 136: 1303-1314.

45. Corbier P., Martikainen P., Pestis J., Härkönen P. 1995. Experimental research on the morphofunctional differentation of the rat ventral prostate: roles of the gonads at birth. Archives of Physiology and Biochemistry, 103: 699-714.

46. Berry S., Isaacs JT. 1984. Comparative aspects of prostate growth and androgen metabolism with aging in the rat versus the dog. Endocrinology, 114: 511-520.

47. Vilamaior PS., Taboga SR., Carvalho HF. Postnatal growth of the ventral prostate in Wistar rats: a stereological and morphometrical study. 2006. Anatomical Record Part A-Discoveries in Molecular Cellular and Evolutionary Biology, 288: 885-92.

48. Labrie F., Sugimoto Y., Luu-The V. 1992. Structure of human type II 5a-reductase gene. Endocrinology, 131: 1571-1573.

49. Martin C., Bean R., Rose K., Habib F., Seckl J. 2001. Cyp7b1 catalyses tha 7a-hydroxylation of dehydroepiandrosterone and 25-hydroxycholesterol in the rat prostate. The Biochemical Journal, 355: 509-515.
50. Bartsch G., Rittmaster RS., Klocker H. 2000. Dihydrotestosterone and the concept of 5areductase inhibition in human benign prostatic hyperplasia. European Urology, 37: 367-380.

51. Weihua Z., Lathe R., Warner M., Gustafsson J.A. 2002. An endocrine pathway in the prostate, ERb, AR, 5a- androstane-3b, 17bdiol and CYP7B1, regulates the prostate growth. Proceedings of the National Academy of Sciences USA, 99: 13589-13594.

52. Huggins C., Hodges CV. 1941. Studies on prostate cancer. The effects of castration, of estrogen and androgen interaction on serum phosphatases in metastatic carcinoma of the prostate. Cancer Research, 1: 293-297.

53. Pelletier G., El-Alfy M. 2000. Immunocytochemical localization of estrogen receptors alpha and beta in the human reproductive organs. The Journal of Clinical Endocrinology and Metabolism, 85: 4835-40.

54. Hellerstedt BA., Pienta KJ. 2002. The current state of hormonal therapy for prostate cancer. A Cancer Journal for Clinicians, 52: 154-79.

55. García-Flórez M., Oliveira CA., Carvalho HF. 2005. Early effects of estrogen on the rat ventral prostate. Brazilian Journal of Medical and Biological Research, 38: 487-497.

56. Simpson E., Rubin G., Clyne C. 1999.. Local estrogens biosynthesis in males and females. Endocrine-Related Cancer, 6: 131-137.

57. Takase Y., Levesque MH., Luu-The V., El-Alfy M., Labrie F., Pelletier G. 2006. Expression of Enzymes Involved in Estrogen Metabolism in Human Prostate. Journal of Histochemistry $\mathcal{E}$ Cytochemistry, 54: 911-921.

58. Zondek T., Mansfield MD., Attree SL., Zondek LH. 1986. Hormone levels in the foetal and neonatal prostate. Acta Endocrinologica, 112: 447-56.

59. Houtsmuller EJ., Juranek J., Gebauer CE., Slob K., Rowland DL. 1994. Males located caudally in the uterus affect sexual behavior of male rats in adulthood. Behavior Brain Research, 62:119-25.

60. Nonneman DJ., Ganjam VK., Welshons WV., Vom Saal FS. 1992. Intrauterine position effects on steroid metabolism and steroid receptors of reproductive organs in male mice. Biology of Reproduction, 47: 723-729.

61. Howdeshell KL., Hotchkiss AK., Thayer KA., Vandenbergh JG., vom Saal FS. 1999. Exposure to bisphenol A advances puberty. Nature, 401: 763-764.

62. Woodham C., Birch L., Prins GS. 2003. Neonatal estrogen exposure down-regulates prostatic androgen receptor through a proteosome-mediated protein degradation pathway. Endocrinology, 144: 4841-4850. 
63. Quigley CA, DeBellis A, Marschke KB, ElAwady MK, Wilson EM \& French FF 1995 Androgen receptor defects: historical, clinical and molecular perspectives. Endocrine Reviews 16: 271-321.

64. Omoto Y., Imamov O., Warner M., Gustaffson JA. 2005. Estrogen Receptor a and imprinting of the neonatal mouse ventral prostate by estrogen. Proceedings of the National Academy of Sciences USA, 102: 1484-1489.

65. Weihua Z., Makela S., Andersson C., Salmi S. 2001. A role for estrogen receptor $b$ in the regulation of growth of the ventral prostate. Proceedings of the National Academy of Sciences USA, 98: 6330-6335.

66. J. Singh, D. J. Handelsman 1999. Morphometric studies of neonatal estrogen imprinting in the mature mouse prostate. Journal of Endocrinology, 162: 39-48.

67. Glass CK., Rose DW., Rosenfeld MG. 1997. Nuclear receptor coactivators. Current Opinion in Cell Biology, 9: 222-232.
68. Torchia J., Glass C., Rosenfeld MG. 1998. Coactivators and co-repressors in the integration of transcriptional responses. Current Opinion in Cell Biology, 10: 373-383.

69. Leo C., Chen JD. 2000. The SRC family of nuclear receptor co-activators. Gene, 245: 1-11.

70. Yamashita S. 2004. Ontogenic expression of estrogen receptor coactivators in the reproductive tract of female mice neonatally exposed to diethylstilbestrol. Reproductive Toxicology, 18: 275-284

71. Risbridger GP, Almahbobi GA, Taylor RA. 2005. Early prostate development and its association with late-life prostate disease. Cell Tissue Research, 322: 31-45.

72. J. Singh, D. J. Handelsman 1999. Imprinting by Neonatal Sex Steroids on the Structure and Function of the Mature Mouse Prostate. Biology of Reproduction 61: 200-208. 
Universidad

Surcolombiana

\section{OFERTAS ACADÉMICAS FACULTAD DE SALUD UNIVERSIDAD SURCOLOMBIANA}

\section{PREGRADO}

\section{PROGRAMA DE MEDICINA}

$\begin{array}{ll}\text { Registro SNIES: } & 338 \\ \text { Jornada: } & \text { Diurna } \\ \text { Duración: } & 12 \text { semestres } \\ \text { Metodología: } & \text { Presencial } \\ \text { Sede: } & \text { Neiva } \\ \text { Título a Otorgar: } & \text { Médico (a) } \\ \text { Acto por el cual se constituyo el Programa: }\end{array}$

Acuerdo No. 100 de 1982

Acuerdo de Acreditación: Resolución No. 6455 del 23 de julio de 2010

Ministerio de Educación Nacional

Año de Iniciación de actividades Docentes

1982

\section{PROGRAMA DE ENFERMERÍA}

Acreditación de alta calidad:

Resolución 7444 del Ministerio de Educación Nacional de 30 noviembre de 2007

Jornada: Diurna

Duración: $\quad 10$ semestres

Metodología: Presencial

Sede: Neiva

Título que otorga: Enfermera - Enfermero

\section{Información}

Email: enfermeria@usco.edu.co

Dirección: Calle 9 con Carrera 14, contiguo al Hospital Universitario Hernando

Moncaleano Perdomo

Teléfono: (098) 8718310 Extensión 3108

Telefax: (098) 8717991 